\title{
Evaluation of the Safety of High-Salt Wastewater Treatment in Coal Chemical Industry Based on the AHP Fuzzy Method
}

\author{
Shijun Guo, ${ }^{1,2}$ Shubham Sharma $\mathbb{D}^{3},{ }^{3}$ Alibek Issakhov, ${ }^{4}$ and Nima Khalilpoor ${ }^{5}{ }^{5}$ \\ ${ }^{1}$ Shanghai University of Finance and Economics, Shanghai 200433, China \\ ${ }^{2}$ Space Culture Research Center, Guilin University of Aerospace Technology, Guilin 541004, China \\ ${ }^{3}$ Deptt. of Mechanical Engg., IK Gujral Punjab Technical University, Main Campus, Kapurthala 144603, India \\ ${ }^{4}$ Faculty of Mechanics and Mathematics, Department of Mathematical and Computer Modelling, \\ Al-Farabi Kazakh National University, Almaty, Kazakhstan \\ ${ }^{5}$ Department of Energy Engineering, Graduate School of the Environment and Energy, Science and Research Branch, \\ Islamic Azad University, Tehran, Iran
}

Correspondence should be addressed to Nima Khalilpoor; nimakhalilpoor@gmail.com

Received 22 April 2021; Revised 23 June 2021; Accepted 29 September 2021; Published 7 December 2021

Academic Editor: Ibrahim H. Alsohaimi

Copyright (c) 2021 Shijun Guo et al. This is an open access article distributed under the Creative Commons Attribution License, which permits unrestricted use, distribution, and reproduction in any medium, provided the original work is properly cited.

\begin{abstract}
Aim. Epichlorohydrin (ECH) is a widely used chemical product. The production of glycerol has its irreplaceable advantages. With the development of biodiesel industry, it will become the main trend of ECH production in the future. Methods. A vacuum evaporation device is built to investigate the effect of evaporation on the treatment of this kind of high-salt wastewater, and the feasibility of the thermodynamic equation of the simulation process is verified. Process. An AHR fuzzy mathematics evaluation algorithm is used to compare experimental values with simulated numerical values in brine. Results and Conclusions. In the multieffect evaporation process simulation with glycerin-containing brine, the amount of salt precipitated by unit steam energy is arranged in order from more to less than that of seven-effect parallel flow evaporation, is greater than five-effect parallel flow evaporation, and is larger than three-effect parallel flow evaporation, which shows that the increase of validity number is beneficial to the utilization of heat.
\end{abstract}

\section{Introduction}

As a chemical product, epichlorohydrin $(\mathrm{ECH})$ is very useful. It is the main raw material for the production of glass fiber-reinforced plastics, electrical insulation products, chlorine alcohol rubber, nitroglycerin explosives, and epoxy resins. It can also be used as plasticizer, surfactant, stabilizer, medicine, and solvent, and cellulose ether of cellulose ester resin and cellulose ether, and so on [1]. Due to its wide range of applications, large market demand, and long-term supply of tension, the production of epichlorohydrin has a good momentum of development. The total production capacity of epichlorohydrin in the world in 2008 reached approximately 1.81 million $\mathrm{t} / \mathrm{a}$, and it is estimated that by 2012 , it will exceed 2.3 million $\mathrm{t} / \mathrm{a}$ [2]. It can be seen that the glycerol production of cyclic chlorine has its irreplaceable advantages. This process, along with the development of the biodiesel industry, is bound to become the main trend for the production of chlorine in the future. There have been a number of patents and plans put into practice [3]. Dow's patent for glycerol-based ECH (GTC) requires only half of the chlorine and reduces environmental pollution. Compared with traditional processes, it has great cost and environmental friendliness [4]. Solvay's new plant Epicero process uses a new series of catalysts and contains several patent applications. The Czech chemical metallurgy joint company reported a continuous cycle reaction process of glycerol to ECH [5]. Japan's process plant has begun to operate one after another. Jiangsu Yangnong Chemical Co., Ltd. has built a 60,000 t/a plant in 2006. Formosa Plastics Group, Dow Chemical Fine Chemicals (Shanghai) Co., Ltd., and Guangxi Tiandong Petrochemical Industrial Park all 
directly produce glycerin as raw materials. ECH has a related production plan [6].

Many chemical and pharmaceutical companies produce wastewater containing large amounts of salt and containing many chemicals during the production process. Due to the complex chemical composition, high organic concentration, and high-salt content, these wastewater chemistries are difficult to directly process using more economical biochemical processes, and it is difficult to achieve satisfactory results using traditional wastewater treatment technologies [7]. However, this type of wastewater is treated by evaporation to achieve the purpose of recovering condensed water and inorganic salts of organic matter. There are many examples of evaporative treatment of high-salt wastewater [8]. The wastewater of chemical additives production is difficult to biodegrade, and the concentration, alkalinity, and salt content are high. The pretreatment process is critical, and vacuum evaporation will be used. The volatile components can be distilled off by the evaporation operation, so that a large amount of salt and organic substances are reduced in the distillate. In Hebei Province, a chemical additives Co., Ltd., a self-modified evaporator can effectively achieve this goal. First of all, the wastewater discharged from the production process is separately adjusted, so that the $\mathrm{pH}$ is adjusted to about 8 before evaporation, and then, $0.6-0.8 \mathrm{MPa}$ of saturated steam is added to the self-aligned evaporator as raw steam, followed by vacuum evaporation and concentration. During the evaporation process, the precipitated salt and the evaporated residue at the bottom of the evaporation vessel are periodically discharged to the outside of the vessel. The specific treatment effect is that the amount of wastewater entering the evaporator is $42 \mathrm{~m}^{3} / \mathrm{d}$, and the COD is about $28300 \mathrm{mg} / \mathrm{L}$. The evaporated distillate is condensed and then collected in a collection tank. The amount of water is $30-35 \mathrm{~m} 3 / \mathrm{d}$, and the COD is $1800-2000 \mathrm{mg} / \mathrm{L}$.

An experimental device is designed and constructed for measuring the bubble point of a saturated sodium chloride solution containing glycerol, examining the feasibility of the device to detect the boiling point of a salt solution under a certain pressure and concentration. Based on an externally heated evaporator, a multieffect evaporation of the brine system and glycerin-containing brine is simulated by the chemical process using PRO II software. The model threeeffect cocurrent evaporation process, five-effect cocurrent evaporation process, and seven-effect cocurrent evaporation process were used. The effects of different multieffect evaporation processes on steam economy of multieffect evaporation are investigated. The following conclusions are drawn. Based on PRO II simulations, it is found that in the brine system or in the glycerin brine system, the amount of salt precipitated by unit steam energy is arranged in order from much to less: the seven-effect parallel flow evaporation is greater than the five-effect parallel flow evaporation which is greater than the three-effect parallel flow evaporation. From the point of view of heat utilization, the increase of validity is beneficial to the utilization of steam and the precipitation of salt. The purpose of reducing energy consumption is to study the economy of steam and select the appropriate flow.

\section{Methodology}

2.1. Fuzzy Mathematics Evaluation Algorithm. ECH production wastewater is a common industrial saponification wastewater, with high salt, high COD content, and other difficult characteristics [9]. In the former Soviet Union in 1981, a method for treating the wastewater was reported. The method includes first aggregating calcification in a sedimentation tank and then filtering out a clear liquid containing $\mathrm{CaCl}_{2}$ at a concentration of from 5 to 10 to 250 to $360 \mathrm{~g} / \mathrm{L}$. The clear solution was concentrated by evaporation while crystallizing the organic chloride. Esch also invented a treatment method for ECH production wastewater, which includes the recovery of salt compounds, including pretreatment, evaporation and condensation, coarse crystallization, and fine crystallization [10]. In the preconcentration stage, the falling film evaporator is used, and evaporation is also used to achieve the purpose of concentrating the wastewater to precipitate salts (Figure 1). Some scholars have used other processes and low-temperature multiple-effect evaporation (LT-MED) combination process to treat heavysalt and high-hardness heavy-oil wastewater. The results show that it is feasible to use LT-MED as the core technology to treat heavy oil wastewater and can be used for thermal recovery boilers.

A thing either belongs to the set A or does not belong to the set $\mathrm{A}$, and no other belongs to the relation. In modern science and engineering applications, the concept of fuzzy sets often occurs, that is, a certain thing a belongs to set $A$ to a certain degree. This idea is the basis of fuzzy set. The concept of fuzzy sets was proposed by the cybernetics expert Professor Lotfi A Zadeh in 1965. At present, fuzzy logic has been widely used in various fields such as science, engineering, agriculture, and medicine. The description of things in the real world is not always as accurate as possible. Professor Zadeh pointed out that "When the complexity of the problem increases, the precise description will lose meanings, and meaningful description will lose accuracy."

Fuzzy data are obfuscated by the membership function. The commonly used membership functions include triangle membership function, bell membership function, Gaussian membership function, and Sigmund-type membership function. Gauss membership function is used to fuzzily the indicator data because the function is continuous, symmetrical, and has good resolution. The mathematical expression of the Gauss membership function is

$$
f(x)=e^{(x-c)^{2} / 2 \sigma^{2}} .
$$

The shape of the Gauss membership function with different $c$ and $\sigma$ parameters is consistent with the shape of the probability density function of the normal distribution [11].

$$
f(x)=\frac{(x-c)^{2}}{2 \sigma^{2}} .
$$




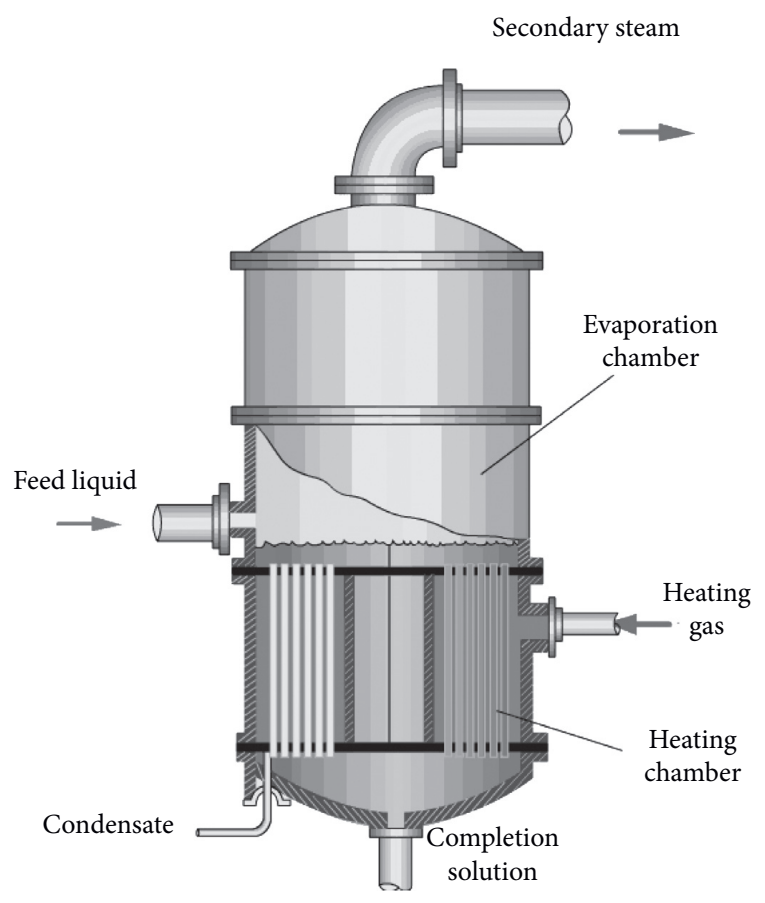

Figure 1: Design of the vacuum evaporator.

From its analytical formula, it can be deduced that when $c$ changes, the membership function curve becomes wider and the shape does not change, but only shifts left and right, and when $\sigma$ changes, the curve becomes wider or narrower, and the horizontal position remains unchanged [12].

$$
f(x)=2(x-c) \sigma^{2} .
$$

So, when the index data are blurred, the $\sigma$ and $c$ parameters can be changed according to actual conditions or requirements, so that when the data is blurred, the degree of membership of different fuzzy sets (intervals) changes accordingly [13].

$$
f(x)=2 x \sigma^{e} .
$$

Pattern recognition mainly includes stratification of index systems and hierarchical classification of indicators. The stratification refers to the hierarchical division of the index system. The index system is divided into four levels: A, B, C, and D. The index division is to divide the actual data of the indicator into $\mathrm{N}$ segments according to the range of values. Each segment is represented by a membership function [3]. An accurate actual experiment or survey data can be fuzzified by such a set of membership functions and become fuzzy data. If the actual data range is divided into three segments, it means that it belongs to three fuzzy sets and can be represented by three membership functions. Generally, the corresponding physical meanings are "very small," "medium," and "larger". In this study, the actual data are divided into four fuzzy sets and expressed by four membership functions. The corresponding physical meanings are "better," "good," "general," and "poor." The classification of indicators is given in tables [14-17].
The fuzzy inference system (FIS) can be constructed using the newfis() function and providing in the MatLab fuzzy logic toolbox to obtain the data structure of the fuzzy inference system of the problem. Its contents include fuzzy and or operations and resolution algorithms. These attributes can be defined directly by the newfls() function or after the definition [18]. There are two types of HS-Mamdani and Sugeno. The main difference between the two methods is that the FIS output membership function of the Sugeno class can only be linear or the oriented FIS can be arbitrary. The Mamdani method is intuitive, it is now widely accepted, and it is very similar to people's thinking habits, so the Mamdani type of FIS is used. After defining the fuzzy inference system (FIS), it is possible to add system input and output variables and their range of values. In this study, the input variables are each evaluation index and the output is the evaluation value [19].

There are four levels of the regional developmental ecosystem suitability index system set up in this study, which are denoted by A, B, C, and D, respectively. Adopt a bottomup, layer-by-layer recursive method to evaluate the entire region's ecological system suitability. First, use the D-layer index as input and obtain the C-level evaluation output. Then, use the C-layer index as input and obtain the B-level. The evaluation output finally obtains the evaluation output of layer $\mathrm{A}$.

\subsection{Wastewater Treatment Process Simulation Basic} Algorithm. So far, the commonly used chemical process simulation methods are the following: first is the sequential module method. The sequential module method is the most commonly used process simulation algorithm in engineering applications. The main steps include the following: calculate the unit modules through which the feed streams are passed in order, until the final material flow, and then, you can get all the material parameters in the system. Since the flow direction of the logistics is certain, the output logistics parameters can only be calculated based on the input logistics parameters. The existence of the recycling logistics requires more complex iterative calculations. The specific content is to cut off the recycling logistics and then determine the fracture logistics and operation sequence until the entire process converges. The advantages are that a variety of specialized algorithms can be used to solve the model equations of a certain unit module, which has the characteristics of high efficiency; both the accelerating lamination and the direct iteration can achieve the purpose of stable convergence; the simulation in the physical process of logistics and modules information flow can correspond to each other, easy to understand; and the process of diagnosing errors is relatively simple.

The second is the simultaneous equations method. The description of the chemical process system will involve the establishment of mathematical models. This process requires the establishment of a large number of equations. The simultaneous set up of these equations is called simultaneous equations. This chemical process simulation method is essentially the establishment and solution of equations. 
Compared to the sequential module method, the simultaneous equation method does not require iterative calculations. The advantages are that faster solution of the equation, flexible and convenient, high efficiency, and easy to implement with dynamic simulation. Disadvantages are strict requirements on initial values, and the process of diagnosing errors is complex and difficult to achieve.

The third is the simultaneous module method. The simultaneous module method is also called the double-layer method. The first layer refers to the process level and the second layer refers to the module level. From the abstract classification of the model, it is divided into the "simplified model" and "strict model." The advantage of the simplified model is that it can easily solve some input data, share these input data with the rigorous model, and then obtain the output data through the rigorous model and recalculate into the mathematical model of the simplified model. This method inherits the advantages of the sequential module method and the simultaneous equation method, that is, it can use the existing unit operation module, and it can avoid loop iterations and achieve universalization. PRO/II is calculated using a sequential module approach. When a chemical process is simulated, the first task is to determine the process simulation software. The basis for the determination usually includes physical parameters involving materials, thermodynamic methods, and unit modules. The accuracy and flexibility of the required results are also not negligible. The accuracy of the results of different process simulation software is not only related to the system itself but also has a lot to do with the method of use. Different software provides various optional thermodynamic methods and unit modules. If the method is used improperly, it will result in larger errors. Under normal circumstances, the results of running different process simulation software are not much different. The difference in the accuracy of results often lies in the selection of the unit module and the determination of the thermodynamic method.

Process simulation system software is used for process simulation. The following steps are often used: first, analyze the target simulation problem, combine the actual situation of the target simulation problem, convert it into a mathematical model, analyze the known and solved problems, and select the appropriate process simulation software. There are differences in the use of each software, and the determination of the software will help us in the next step; Second, establish a simulation process, use the method provided by the process simulation software to establish the simulation process, that is, establish the connection sequence of the relevant unit modules and logistics. Third, participate in the process of components. In conjunction with the substances involved in the actual problem, enter the corresponding components in the simulation system and determine the thermodynamic model; inappropriate thermodynamic methods will lead to the inaccurate simulation process and data, according to the actual situation. Choosing the most suitable thermodynamic method is the prerequisite for successful simulation. Finally, input known parameters. This includes the original logistics and unit module parameters, which can be input to the chemical process simulation.

\section{Results and Discussion}

Pure water was added and the pressure was increased from $20 \mathrm{kPa}$ to normal pressure. Through the above experimental apparatus and experimental procedures, the boiling point corresponding to a certain pressure was measured, and the influence of the increase in pressure on the boiling point was examined.

As can be seen from Figure 2, the pure water measured in the experiment is basically consistent with the literature data. The results show that the experimental device process is feasible to detect the bubble point of the solution under a certain pressure and concentration. From the viewpoint of simplifying the calculation, it can be considered that in this concentration range, the bubble point of the saturated aqueous sodium chloride solution is equal to the bubble point of the saturated sodium chloride solution. The bubble point of saturated sodium chloride solution containing glycerin was measured by adjusting the pressure of different systems. The boiling point of the water measured by this device is basically consistent with the literature data obtained. The results show that the device is capable of detecting the bubble point of the solution under a certain pressure. Use the above experimental procedure to measure the bubble point of saturated sodium chloride solution with different glycerol concentrations. When pressure is constant, the increase of glycerol concentration will increase the bubble point slowly, but the increase is not obvious. When the glycerol concentration is constant, the increase in pressure will increase the bubble point. Compared with the bubble point of the saturated sodium chloride solution without glycerol, the absolute pressure is in the range of $20 \mathrm{kPa}$ to atmospheric pressure, and the addition of glycerol concentration of $11-500 \mathrm{~g} / \mathrm{L}$ will increase the bubble point of the solution by $0-5^{\circ} \mathrm{C}$. To simplify the calculation, it is considered that when the glycerol concentration is less than $100 \mathrm{~g} / \mathrm{L}$, the bubble point of the saturated sodium chloride solution is equal to the bubble point of the saturated sodium chloride solution. Determination of COD in distillate and conversion to glycerol is given in Table 1 .

From the above table, it can be seen that the COD content in the distillate is almost zero, and it can be regarded that the distillate after the vacuum evaporation treatment does not substantially contain glycerin organics. Using $\mathrm{PRO} / \mathrm{II}$ to simulate the bubble point of saturated sodium chloride brine, the result is compared with the bubble point obtained by the gas-liquid equilibrium experiment, as shown in Figure 3 [17-19].

The simulated data and the experimental data were basically in agreement and proved that the application of the thermodynamic equation to the brine system is feasible. The main economic indicators of evaporating operation are measured by evaporating salt content/raw steam, and the comparison of three-effect parallel flow, five-effect parallel flow, and seven-effect parallel flow is given in Table 2 .

From the table, we can see that in the saltwater system, the unit of raw steam can precipitate the salt in order of decreasing from seven to more than five and more than three. This shows that, considering the use of heat, the 


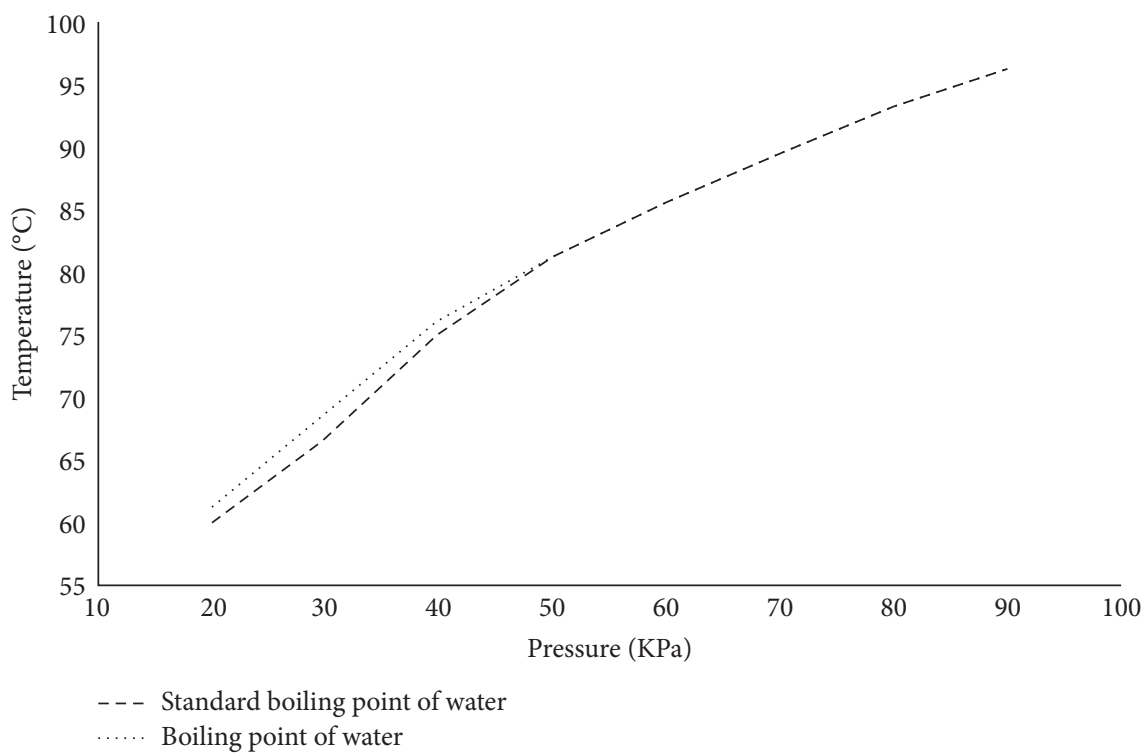

Figure 2: Pressure-boiling point diagram of water.

TABLE 1: The concentration of COD and glycerol in the distillate.

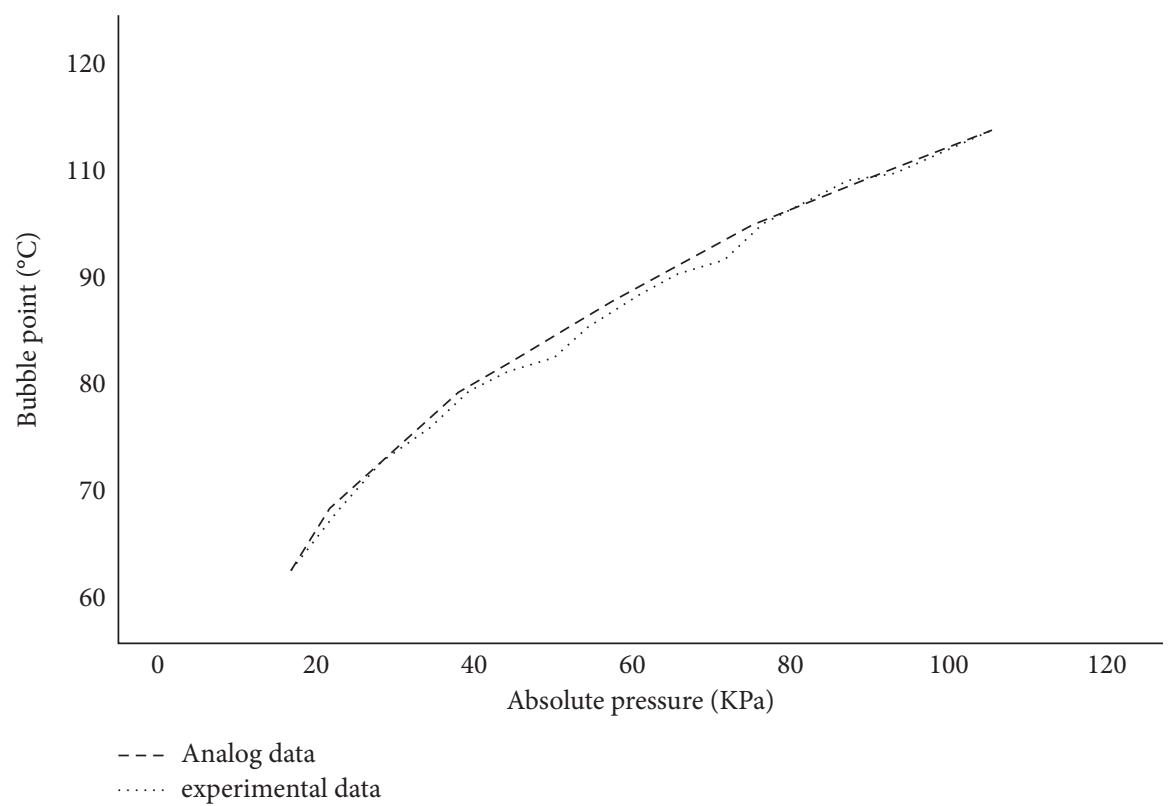

Figure 3: Brine system bubble simulated data compared with the experimental data.

TABLE 2: Comparison of steam generation and discharge of different efficiency in the brine system.

\begin{tabular}{lcccccrr}
\hline $\begin{array}{l}\text { Technological } \\
\text { process }\end{array}$ & Water & $\begin{array}{c}\text { Discharge flow }(\mathrm{kmol} / \mathrm{h}) \\
\text { Shloride }\end{array}$ & $\begin{array}{c}\text { Hydrogen } \\
\text { chloride }\end{array}$ & $\begin{array}{c}\text { Sodium } \\
\text { hydroxide }\end{array}$ & $\begin{array}{c}\text { Steam generating } \\
(\mathrm{kmol} / \mathrm{h})\end{array}$ & $\begin{array}{c}\text { Precipitated salt } \\
(\mathrm{kmol} / \mathrm{h})\end{array}$ & $\begin{array}{c}\text { Salt/steam } \\
\text { Three-effect flow }\end{array}$ \\
\hline Five-effect flow & 0.3596 & 0.015 & 0.0299 & 0.0299 & 5 & 0.058 \\
Seven-effect flow & 0.0862 & 0.0188 & 0.0375 & 0.0375 & 3.7 & 0.29 & 0.25 \\
\hline
\end{tabular}




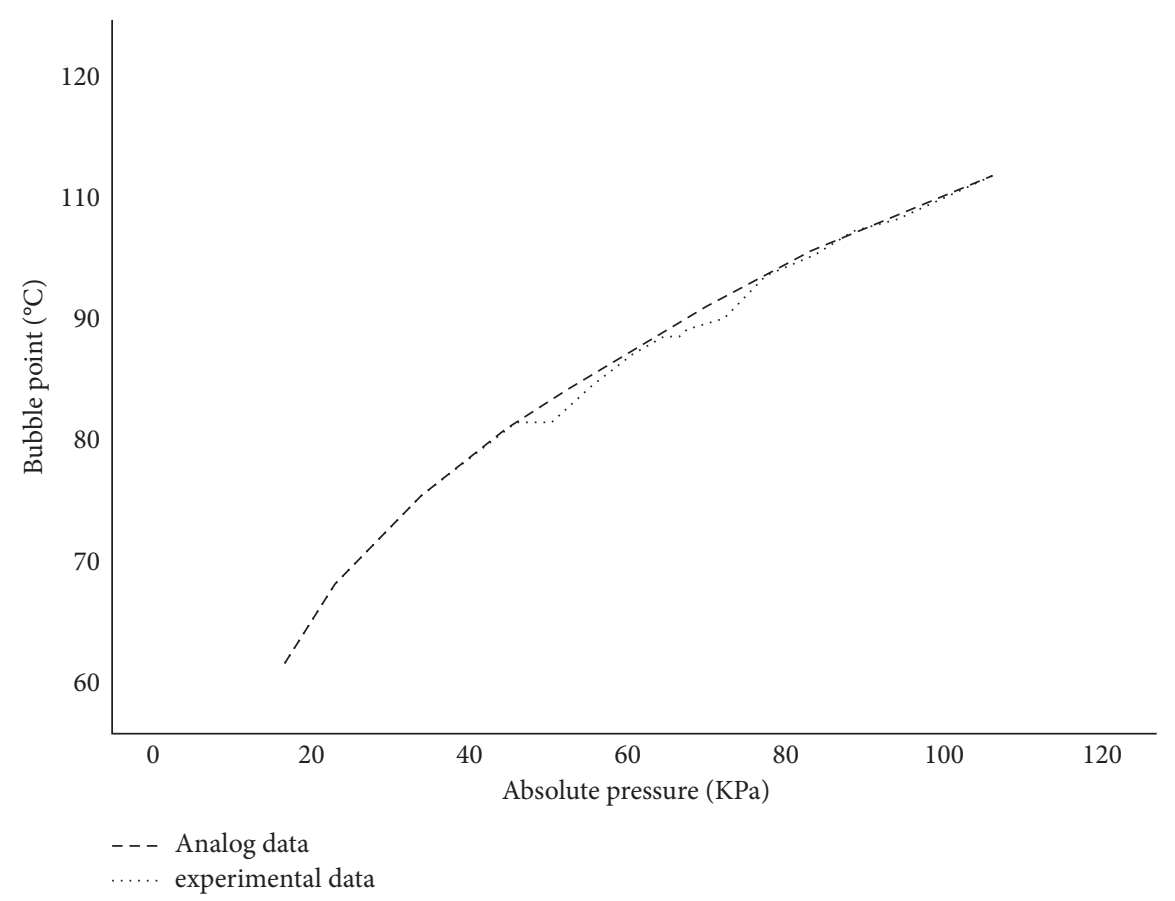

Figure 4: Glycerol saline system bubble simulation data and experimental data.

TABLE 3: Comparison of different steam generation and discharging conditions of the glycerin brine system.

\begin{tabular}{lcccccc}
\hline $\begin{array}{l}\text { Technological } \\
\text { process }\end{array}$ & Water & $\begin{array}{c}\text { Sodium } \\
\text { chloride }\end{array}$ & $\begin{array}{c}\text { Hydrogen } \\
\text { chloride }\end{array}$ & $\begin{array}{c}\text { Sodium } \\
\text { hydroxide }\end{array}$ & $\begin{array}{c}\text { Steam generating } \\
(\mathrm{kmol} / \mathrm{h})\end{array}$ & $\begin{array}{c}\text { Precipitated salt } \\
(\mathrm{kmol} / \mathrm{h})\end{array}$ \\
\hline Three-effect flow & 0.182 & 0.007 & 0.003 & 0.016 & 5.000 & 0.300 \\
Five-effect flow & 0.346 & 0.014 & 0.003 & 0.030 & 3.700 & 0.060 \\
Seven-effect flow & 0.538 & 0.022 & 0.003 & 0.046 & 3.000 & 0.067 \\
\hline
\end{tabular}

increase in the number of efficiencies favors the use of steam and the precipitation of salt. Using PRO/II to simulate the bubble point of saturated sodium chloride solution containing $11 \mathrm{~g} / \mathrm{L}$ of glycerol, the results are compared with the bubble point obtained from the gas-liquid equilibrium experiment, as shown in Figure 4.

The glycerol-containing sodium chloride water systems can be modeled by using this thermodynamic equation. If the main economic indicators of evaporating operation are measured by evaporating salt content/raw steam, the comparison of three-effect parallel flow, five-effect parallel flow, and seven-effect parallel flow is given in Table 3 .

From this table, it can be seen that in the system containing glycerol, the unit steam energy precipitates the salt in order from more to less in order of seven-effect, five-effect, and three-effect.

\section{Conclusions}

An experimental device is designed and constructed for measuring the bubble point of a saturated sodium chloride solution containing glycerol, examining the feasibility of the device to detect the boiling point of a salt solution under a certain pressure and concentration. Based on an externally heated evaporator, a multieffect evaporation of the brine system and glycerin-containing brine is simulated by the chemical process using PRO II software. The model threeeffect cocurrent evaporation process, five-effect cocurrent evaporation process, and seven-effect cocurrent evaporation process were used. The effects of different multieffect evaporation processes on steam economy of multieffect evaporation are investigated. Based on PRO II simulations, it is found that in the brine system or the glycerin brine system, the amount of salt precipitated by unit steam energy is arranged in order from much to less: the seven-effect parallel flow evaporation is greater than the five-effect parallel flow evaporation which is greater than the three-effect parallel flow evaporation. From the point of view of heat utilization, the increase of validity is beneficial to the utilization of steam and the precipitation of salt. The purpose of reducing energy consumption is to study the economy of steam and select the appropriate flow.

\section{Data Availability}

No data were used to support this study.

\section{Conflicts of Interest}

The authors declare that they have no conflicts of interest. 


\section{References}

[1] H. Wei, G. Liu, and T. Yong, "Wastewater treatment evaluation for enterprises based on fuzzy-AHP comprehensive evaluation: a case study in industrial park in Taihu Basin, China," SpringerPlus, vol. 5, no. 1, p. 907, 2016.

[2] W. Liang, C. Ying, L. Min, and Y. Zhai, "Comprehensive performance evaluation of municipal wastewater treatment plants," Chinese Journal of Environmental Engineering, vol. 10, no. 1, pp. 490-494, 2016.

[3] M. A. Dursun, "Fuzzy approach for the assessment of wastewater treatment alternatives," Engineering Letters, vol. 24, no. 2, pp. 231-236, 2016.

[4] J. Fernandez de Canete, P. Del Saz-Orozco, R. Baratti, M. Mulas, A. Ruano, and A. Garcia-Cerezo, "Soft-sensing estimation of plant effluent concentrations in a biological wastewater treatment plant using an optimal neural network," Expert Systems with Applications, vol. 63, no. C, pp. 8-19, 2016.

[5] K. Liu, Y. Hu, and J. Lei, "The chemical product mode transition of the air DBD driven by AC power: a plausible evaluation parameter and the chemical behaviors," Physics of Plasmas, vol. 24, no. 10, p. 103513, 2017.

[6] S. Ditommaso, M. Giacomuzzi, E. Ricciardi, R. Garbuio, and C. M. Zotti, "The role of chemical products at low doses in preventing the proliferation of bacteria in dental unit waterlines: the ICX experience," Journal of Water and Health, vol. 16, no. 1, pp. 150-158, 2018.

[7] S. Cignitti, S. S. Mansouri, J. M. Woodley, and J. Abildskov, "Systematic optimization-based integrated chemical productprocess Design framework," Industrial \& Engineering Chemistry Research, vol. 57, no. 2, pp. 677-688, 2018.

[8] J.-B. Xu, J.-P. Chen, S.-L. Wu, Y.-H. Pan, W. Wang, and Q.-Q. Luo, "Prediction of large deformation behavior in tunnels based on AHP-FUZZY method and numerical simulation method," Geotechnical \& Geological Engineering, vol. 36, no. 1, pp. 151-163, 2018.

[9] A. A. Aghapour, G. Moussavi, and K. Yaghmaeian, "Degradation and COD removal of catechol in wastewater using the catalytic ozonation process combined with the cyclic rotatingbed biological reactor," Journal of Environmental Management, vol. 157, pp. 262-266, 2015.

[10] P. M. Vallejo LLamas and P. Vega, "Analytical fuzzy predictive control applied to wastewater treatment biological processes," Complexity, vol. 2019, Article ID 5720185, 29 pages, 2019.

[11] M. Hammer and M. Hammer, Water and Wastewater Technology, Prentice-Hall, New York, NY, USA, 2005.

[12] M. Yao, Z. Li, X. Zhang, and L. Lei, "Polychlorinated biphenyls in the centralized wastewater treatment plant in a chemical industry zone: source, distribution, and removal," Journal of Chemistry, vol. 2014, Article ID 352675, 10 pages, 2014.

[13] J. Shi, C. Xu, Y. Han, and H. Han, "Case study on wastewater treatment technology of coal chemical industry in China," Critical Reviews in Environmental Science and Technology, vol. 51, no. 10, pp. 1003-1044, 2020.

[14] A. E. Anqi and A. Mohammed, "Evaluating critical influencing factors of desalination by membrane distillation process-using multi-criteria decision-making," Membranes, vol. 11, p. 164, 2021.

[15] R. R. Tan, K. B. Aviso, A. P. Huelgas, and M. A. B. Promentilla, "Fuzzy AHP approach to selection problems in process engineering involving quantitative and qualitative aspects,"
Process Safety and Environmental Protection, vol. 92, no. 5, pp. 467-475, 2014.

[16] European Commission, Integrated Pollution Prevention and Control, Reference Document on Best Available Techniques in the Chlor-Alkali Manufacturing Industry, European Commission, Brussels, Belgium, 2001.

[17] S. D. Pohekar and M. Ramachandran, "Application of multicriteria decision making to sustainable energy planning-A review," Renewable and Sustainable Energy Reviews, vol. 8, no. 4, pp. 365-381, 2004.

[18] H. An, Z. Liu, X. Cao et al., "Mesoporous lignitecoke as an effective adsorbent for coal gasification wastewater treatment," Environmental Sciences: Water Research \& Technology, vol. 3, no. 1, pp. 169-174, 2016.

[19] G. Boczkaj and A. Fernandes, "Wastewater treatment by means of advanced oxidation processes at basic $\mathrm{pH}$ conditions: a review," Chemical Engineering Journal, vol. 320, pp. 608-633, 2017. 